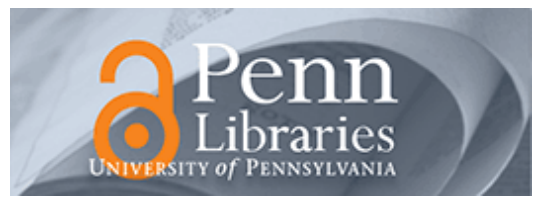

University of Pennsylvania ScholarlyCommons

Marketing Papers

Wharton Faculty Research

December 1992

\title{
Editorial Policies for the Publication of Controversial Findings
}

\author{
J. Scott Armstrong \\ University of Pennsylvania, armstrong@wharton.upenn.edu
}

Follow this and additional works at: https://repository.upenn.edu/marketing_papers

\section{Recommended Citation}

Armstrong, J. S. (1992). Editorial Policies for the Publication of Controversial Findings. Retrieved from https://repository.upenn.edu/marketing_papers/109

Postprint version. Published in International Journal of Forecasting, Volume 8, Issue 4, December 1992, pages 543-544.

Publisher URL: http://dx.doi.org/10.1016/0169-2070(92)90064-G

This paper is posted at ScholarlyCommons. https://repository.upenn.edu/marketing_papers/109

For more information, please contact repository@pobox.upenn.edu. 


\title{
Editorial Policies for the Publication of Controversial Findings
}

\author{
Abstract \\ Armstrong and Hubbard (1991), in a survey of editors of 20 psychology journals, found a bias against the \\ publication of papers with controversial findings. The 16 editors who responded said that they received \\ few papers with controversial findings "during the last two years." When they did receive such papers, the \\ reviewers rejected them. Some of these editors expressed dismay over this situation and said that their \\ referees usually rejected such papers. The study encountered only one instance where the reviewers \\ agreed that a paper with controversial findings should be published. The editor who handled this case \\ was blunt: he picked referees who would agree to its publication.

\section{Comments} \\ Postprint version. Published in International Journal of Forecasting, Volume 8, Issue 4, December 1992, \\ pages 543-544. \\ Publisher URL: http://dx.doi.org/10.1016/0169-2070(92)90064-G
}


Published in International Journal of Forecasting, 8, 1992, 543-544.

\title{
Editorial Policies for the Publication of Controversial Findings
}

\author{
J. Scott Armstrong \\ The Wharton School, University of Pennsylvania
}

Armstrong and Hubbard (1991), in a survey of editors of 20 psychology journals, found a bias against the publication of papers with controversial findings. The 16 editors who responded said that they received few papers with controversial findings "during the last two years." When they did receive such papers, the reviewers rejected them. Some of these editors expressed dismay over this situation and said that their referees usually rejected such papers. The study encountered only one instance where the reviewers agreed that a paper with controversial findings should be published. The editor who handled this case was blunt: he picked referees who would agree to its publication.

I believe that part of the problem lies with the roles of the editors and referees. Referees often believe that their job is to decide whether they agree with the results of a study, while editors often believe that their job is to summarize the recommendations of the referees. Such roles are unlikely to lead to the publication of papers with controversial findings. Mahoney's (1977) experiment found that referees rejected papers that had controversial findings. They did so, they reported, because of "poor methodology." Meanwhile, an equivalent sample of referees accepted papers having identical methodology but noncontroversial findings; these referees approved of the technology. Goodstein and Brazis (1970) obtained similar findings.

The Editors of the International Journal of Forecasting are committed to the notion that important advances in the field depend upon the publication of papers with controversial findings. Such papers are sought by the Editors. Unfortunately the supply is limited. Editorial procedures have been instituted to aid in the acceptance of such papers. One procedure is that authors can propose a set of reviewers and the Editors will ask at least one of these to review the paper. Another procedure is the "Note to Referees," where the author is invited to submit the design of the study without results. Referees would review this before they received the results.

A number of authors have provided a list of possible referees. Few have used the "Note to Referees." Perhaps the problem is similar to that noted for psychology journals (Armstrong and Hubbard, 1991); the IJF does not receive many papers that have controversial findings.

In an effort to increase the number of papers with controversial findings, and at the same time provide safeguards against the publication of incorrect findings, I believe that the IJF should add new procedures.

\section{New Editorial Procedures - Some Suggestions}

\section{Decisions on Papers with Controversial Findings}

For papers with controversial findings, the editors, not the referees, should make the decision about publication. I believe that the editorial board should seek important papers and ensure that they are published. The role of the referees in this case is to ensure that the paper is as good as it can be, rather than asking them to make a recommendation about publication.

Papers with controversial findings can be so identified by the authors, by the Editor, or by the Associate Editor handling the paper. 


\section{Encouraging Papers with Controversial Findings}

Associate Editors can commit the journal to a rapid review and accelerated publication for important papers. As safeguards, the $I J F$ can also publish the referees' comments with the paper, or ask other researchers to publish commentary either along with the paper and/or in later issues.

To provide for more rapid replication and examination of controversial findings, I propose the following:

(a) A "Notes" section that will allow for prompt publication of short items,

(b) A "Letters to the Editor" section so that readers may respond quickly to important papers.

These procedures might increase the frequency of publication of papers with controversial findings and increase the attention paid to these papers once published. Hopefully, they may introduce fruitful research directions and have a beneficial effect on practice.

\section{References}

Armstrong, J. S. and R Hubbard (1991), "Does the need for agreement among reviewers inhibit the publication of controversial findings?" Behavioral and Brain Science,. 14, 136-137.

Goodstein, L. and K.L. Brazis (1970), "Credibility of psychologists: An empirical study," Psychological Reports, $27,835-838$.

Mahoney, M. J. (1977), "Publication prejudices: An experimental study of confirmatory bias in the peer review System," Cognitive Therapy and Research, 1, 161-175.

\section{A Response from the Editors}

Scott Armstrong's views on controversial findings are interesting. However, at this time we do not intend to change our existing procedures in any formal sense. Why? Because the problem we face is that too few controversial papers are being written in forecasting. Already the Editors invite authors to submit papers on important topics, using the referees to improve the quality of the argument. Reviewing turnaround is much improved and commentary is invited, when it seems appropriate. It is now up to those who research in forecasting to focus their attention on those significant issues where major controversy exists and where innovative methodologies may lead to important improvements in forecasting theory and practice. If there are authors who are at an early stage in pursuing such questions, they should contact one of the Editors for immediate feedback. 